\title{
How old is streamwater? Open questions in catchment transit time conceptualization, modelling and analysis
}

J. J. McDonnell, ${ }^{1 *}$ K. McGuire, ${ }^{2}$

P. Aggarwal,${ }^{3}$ K. J. Beven, ${ }^{4}$ D. Biondi, ${ }^{5}$

G. Destouni, ${ }^{6}$ S. Dunn, ${ }^{7}$ A. James, ${ }^{8}$

J. Kirchner, ${ }^{9}$ P. Kraft, ${ }^{10}$ S. Lyon, ${ }^{11}$

P. Maloszewski, ${ }^{12}$ B. Newman, ${ }^{1}$

L. Pfister, ${ }^{3}$ A. Rinaldo, ${ }^{14}$ A. Rodhe, ${ }^{15}$

T. Sayama, ${ }^{16}$ J. Seibert, ${ }^{17}$ K. Solomon, ${ }^{18}$

C. Soulsby, ${ }^{19}$ M. Stewart, ${ }^{20}$ D. Tetzlaff, ${ }^{21}$

C. Tobin, ${ }^{22}$ P. Troch, ${ }^{23} \mathrm{M}$. Weiler, ${ }^{24}$

A. Western ${ }^{25} \mathrm{~A}$. Wörman ${ }^{26}$ and

S. Wrede $^{27}$

${ }^{1}$ Institute for Water and Watersheds and Department of Forest Engineering, Resources and Management Oregon State University, Corvallis, OR 97331-5706, USA; School of Geosciences, University of Aberdeen, Aberdeen, Scotland, AB24 3UF UK ${ }^{2}$ Virginia Water Resources Research Center \& Department of Forestry Virginia Tech, Blacksburg, VA 24061, USA ${ }^{3}$ Isotope Hydrology Section, International Atomic Energy Agency, Wagramer Strasse 5. A-1400 Vienna, Austria ${ }^{4}$ Lancaster Environment Centre, Lancaster University, Lancaster LAI 4YQ UK ${ }^{5}$ Dipartimento di Difesa del Suolo, Università dell Capria Arcavacata di Rende (CS), Italy ${ }^{6}$ Departme Calabria, Arcavacata di Rende (CS), Haly Department of Physical Geography \& Quatemary Geology, Stockhol University, SE 106 S1 Stockholm, Sweden Macaulay Institute, Craigiebuckler, Abendeen ABIS 8QH, UK Department of Forestry and Environmental Resources NC State University, Campus Box 8008, Raleigh, NC 27695-8080, USA ${ }^{9}$ Swiss Federal Institute of Technology (ETH), Raemistrasse 101, CH-8092, Switzerland Institute of Landscape Ecology and Resources Management Heinrich-Buff-Ring 26, 35392 Giessen, Germany ${ }^{11}$ Physical Geography and Quaternary Geology, Stockholm University, Villavägen 16, SE-752 36 Uppsala, Sweden ${ }^{12} H M G U$ Munich-Institute of Groundwater Ecology, 85764 Neuherberg, Germany ${ }^{13}$ Department of Environment and Agro-Biotechnologies, Centre de Recherche Public-Gabriel Lippmann, 41 rue du Brill. -4422 Belvar, Luxembourg ${ }^{14}$ Dept of Civil \& Reviroment Ln gine ong Unive Padova. Padova 1-35131, Laly 'S Dision of Hydrology, Uppsala

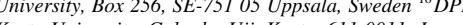
${ }_{17}$ Kyoto University, Gokasho Uji, Kyoto, 611-0011, Japan Hydrology and Climate, Physical Geography Division, Department of Geography University of Zurich-Irchel, Winterthurerstrasse 190, CH-8057 Zurich, Switzerland Department of Geology \& Geophysics, University of Utah, Salt Lake City, UT 84112, USA ${ }^{19}$ University of Edinburgh, Old College South Bridge, Edinburgh EH 9YL, UK ${ }^{20}$ Aquifer Dynamics \& GNS Science, PO Box 30368, Lower Hutt, New Zealand ${ }^{21}$ School of Geosciences, Department of Geography and Environment, University of Aberdeen, Elphinstone Road Aberdeen, AB24 $3 U F$ Scotland, UK ${ }^{22}$ Ecole Polytechnique Fédéral de Lausan EPFL ENAC ISTE EFLUM GR AO 402, Station 2. LPL ENAC ISTE EFLUM GR AO 202 , Station 2 . Hydrology and Water Resources, University of Arizona, Hydrology and Water Resoures, Univerily of Arizd ucson, AZ 8572L USA Institute of Hydrology, University of Freiburg, Fahnenbergplatz, 79098 Freiburg. Environmental Engineering, The University of Melbourne, Victoria 3010 Australia ${ }^{26}$ Division of Water Resources Engineering, Royal Institute of Technology, Teknikringen 76, SE-100 44 Stockholm, Sweden ${ }^{27}$ The Delft University of Technology, Faculty of Civil Engineering and Geosciences, Water Resources Section, P.O. Box 5048, NL-2600 GA Delft, The Netherland

*Correspondence to:

J. J. McDonnell, Institute for Water and Watersheds and Department of Forest Engineering, Resources and Management Oregon State University, Corvallis, OR 97331-5706, USA; School of Geosciences, University of Aberdeen, Aberdeen, Scotland, AB24 3UF UK. E-mail: jeffrey.mcdonnell@oregonstate.edu

Received 17 May 2010

Accepted 17 May 2010

\section{Introduction}

The time water spends travelling subsurface through a catchment to the stream network (i.e. the catchment water transit time) fundamentally describes the storage, flow pathway heterogeneity and sources of water in a catchment. The distribution of transit times reflects how catchments retain and release water and solutes that in turn set biogeochemical conditions and affect contamination release or persistence. Thus, quantifying the transit time distribution provides an important constraint on biogeochemical processes and catchment sensitivity to anthropogenic inputs, contamination and land-use change. Although the assumptions and limitations of past and present transit time modelling approaches have been recently reviewed (McGuire and McDonnell, 2006), there remain many fundamental research challenges for understanding how transit time can be used to quantify catchment flow processes and aid in the development and testing of rainfall-runoff models. In this Commentary study, we summarize what we think are the open research questions in transit time research. These thoughts come from a 3-day workshop in January 2009 at the International Atomic Energy Agency in Vienna. We attempt to lay out a roadmap for this work for the hydrological community over the next 10 years. We do this by first defining what we mean (qualitatively and quantitatively) by transit time and then organize our vision around needs in transit time theory, needs in field studies of transit time and needs in rainfall-runoff modelling. Our goal in presenting this material is to encourage widespread use of transit time information in process studies to provide new insights to catchment function and to inform the structural development and testing of hydrologic models.

\section{What is transit time?}

The terminology on time concepts associated with water movement through catchments can be confusing and a barrier to its use. Water transit time through the system can be defined as:

$$
\tau_{\mathrm{w}}=t_{\mathrm{out}}-t_{\mathrm{in}}
$$

where $\tau_{\mathrm{w}}$ is the elapsed time from the input of water through a system input boundary at time $t_{\text {in }}$ to the output of that water through a system output boundary at time $t_{\text {out }}$. In a catchment, the land surface and the catchment outlet may be considered as the main input and output boundaries for most of the water flow through the catchment (Figure 1). However, the land surface constitutes both a water input boundary and an output boundary for water that experiences evapotranspiration (ET). Considering also the subsurface depth dimension of a catchment, groundwater flow into and out of the catchment system is determined by prevailing groundwater divides and hydraulic gradients, which may vary in time 


\section{J. J. MCDONNELL ETAL.}

and space and differ from the topographically determined catchment boundaries. For general transient flow conditions, water may thus flow into and out from the catchment system through different boundaries that are not all fixed in time and space.

By analogy to the water transit time definition and quantification in Equation (1), one can similarly define and quantify the mean age of a water parcel sampled at any location $x_{\mathrm{w}}$ within the catchment system. The age of a water parcel is then:

$$
\tau_{\mathbf{w}, \mathbf{a}}=t\left(x_{\mathbf{w}}\right)-t_{\text {in }}
$$

where $\tau_{\mathrm{w}, \mathrm{a}}$ is the elapsed time from the water input into the catchment to the time of water sampling at $x_{\mathrm{w}}\left[t\left(x_{\mathrm{w}}\right)\right]$. The transit time is thus the age at the exit of the system (Etcheverry and Perrochet, 2000). Similarly, the age of water sampled at an observation well within a catchment represents the transit time for water through the catchment area to that well.

As water enters the catchment at different points, and the velocity of water varies within the catchment with various processes (Figure 1), a water sample at the catchment outlet or at any point within the catchment is composed of water parcels having different ages. The sample is characterized by a distribution of ages, which equals the distribution of transit times to that sampling point. When this distribution is known, various statistics of interest for different hydrologic problems can be calculated, such as mean and variance, most frequent value (the 'peak'), median and percentiles describing the early arrivals and the late arrivals (the 'tail'). It is important to distinguish clearly between the age distribution in a sample and the age distribution in the system, e.g. between the transit time distribution for water sampled at the catchment outlet and the age distribution for all the water in the catchment. These distributions and their means are equal only in the special case of a completely mixed reservoir under steady-state flow conditions. This is analogous to a human population where the mean age at death (mean transit time) is very different from the mean age of the people still living (mean age in the system).

The mean transit time of a catchment is limited in terms of how much it can tell us about a system's behaviour, because the spreading of a water tracer in space and time, how this depends on the whole transit time distribution, and its tails (short and long transit times). Despite this, the mean transit time can be used to compare the behaviour of different catchments by highlighting broad differences in functioning that often relate to catchment characteristics. This is provided that it is indeed possible to estimate the mean transit time from available data, without making inappropriate assumptions about the nature of the transit time distribution! However, our motivation for understanding transit times is likely to be a strong influence on which elements of the transit time distribution are most important. For example, in the context of understanding how catchment groundwater might recover from remediation of a pollution problem, it may be sufficient to have knowledge of stream baseflow transit
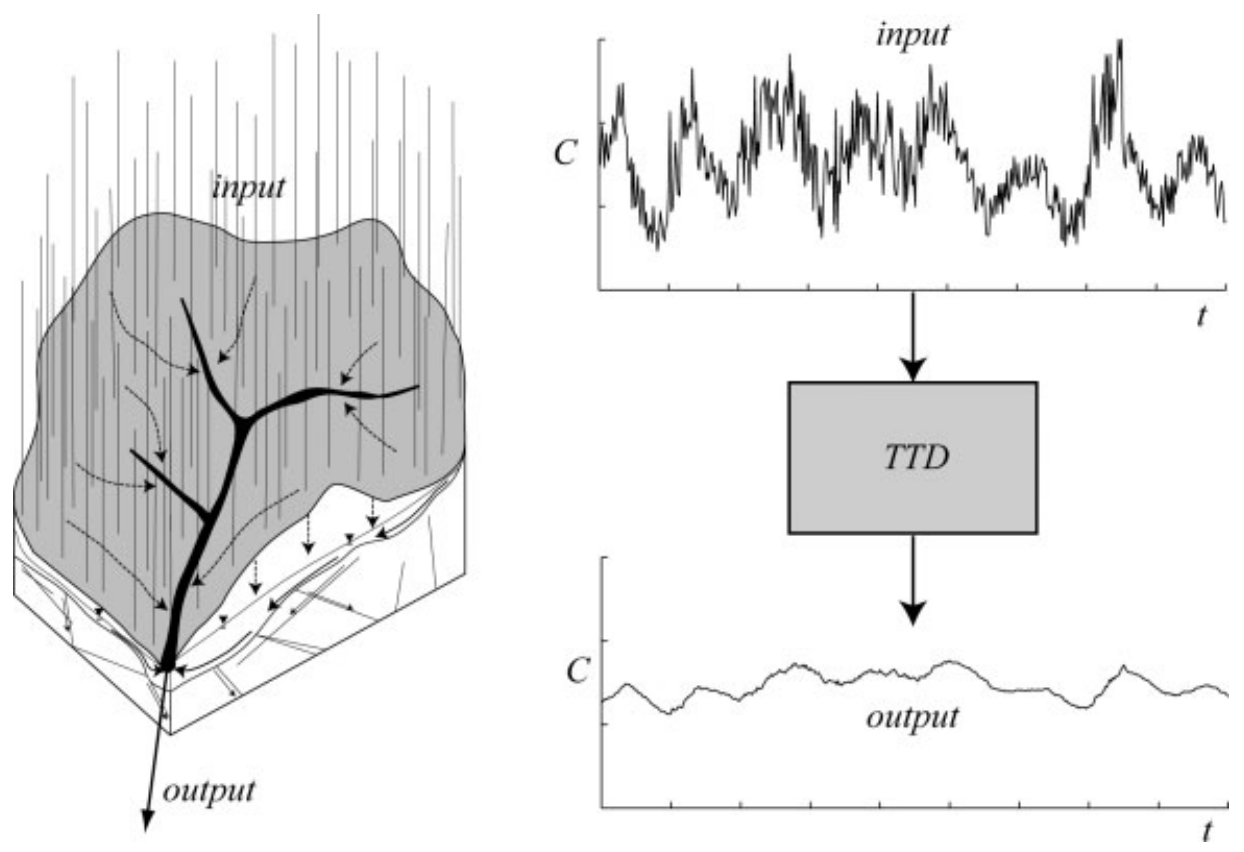

Figure 1. Schematic illustrating that spatially distributed inputs received by a catchment travel along heterogeneous flow paths to the catchment outlet (output). The diagram shows how a conservative tracer input to a catchment will be 'filtered' as the water passes through the system to the catchment outlet, yielding a damped and lagged signal with less high-frequency variation. The transit time distribution (TTD) describes the filtering process 
times, reflecting the long tail of the typical catchment transit time distributions. If understanding of eventdriven pollution is the objective, then transit times of water during high flow events must be understood. In both of these cases, knowledge of the mean transit time would be of little value compared to the entire distribution. The question driving the research should set the focus and requirements of monitoring or modelling activities and it is, therefore, very difficult to generalize about which specific data are necessary to understand transit times for different studies.

Tracers inherently reveal transit time information over limited parts of the entire transit time distribution. We refer specifically to the transit time of tracers that are generally assumed to represent the transit time of water. For example, comparisons between the transit times determined using stable isotopes of water versus tritium $\left({ }^{3} \mathbf{H}\right)$ can differ by an order of magnitude (Stewart et al., 2007; Stewart et al., this issue). The periodicity of the ${ }^{18} \mathrm{O}$ input does not typically provide transit time information greater than about 4-5 years (McGuire and McDonnell, 2006). In contrast, tritium can provide information over a time scale of 1 to more than 100 years. The useful time scale of tracers such as ${ }^{18} \mathrm{O}$ depends on the sampling frequency, the input history (space and time), the fraction of the total volume accessed by the tracer and the part of the hydrograph being sampled. Most existing studies using ${ }^{18} \mathrm{O}$ have a relatively low sample frequency and hence do not provide short-term transit time information.

\section{What is the basic theory for quantifying transit} time?

The input to the catchment is calculated from tracer concentrations in precipitation and infiltration, precipitation and infiltration rates and the spatial-temporal variation of these quantities and processes that influence recharge. Estimates of inputs for large transit times ( $>5$ years) can be derived from relatively simple infiltration models that account for evaporation such as monthly water balance models (Maloszewski et al., 1992). When transit times are short and the tracer input is variable in time, accurate estimates of the recharge mass flux become critical because the input mass flux must balance the mass flux exiting the catchment. Any processes affecting tracer composition (e.g. fractionation due to evaporation or sublimation, occult deposition) must also be included when estimating input composition.

Transit time distributions are typically estimated using time invariant and steady-state assumptions (Shapiro and Cvetkovic, 1988; Cvetkovic and Dagan, 1994). If the storage variability in a catchment is small compared to the long-term mean storage (i.e. storage is roughly constant), then transit time information obtained from the steady-state approach may be similar to that obtained using variable flow modelling approaches (Maloszewski and Zuber, 1993). In variable flow cases, a non-steady-state approach must be considered as, e.g. proposed by Niemi (1977), Zuber (1986) and Foussereau et al. (2001). Non-steady conditions often occur in smaller catchments that have significant storage changes relative to long-term mean storage. When the catchment flow system is nonsteady, the transit time distribution is also time variant. To relax this assumption, one may identify periods (e.g. wet vs dry, different vegetation periods, etc.) when the flow system is relatively constant and estimate parameters (or vary the transit time distribution) accordingly (Stumpp et al., 2009). It is important to note that this may lead to an increased uncertainty of transit time estimates and will mainly provide information about the very short transit times instead of the full distribution. Another simplification that has been adopted in the literature to deal with nonstationarity is to solve the problem in steady state and replace calendar time with the cumulative flow exiting the system (Rodhe et al., 1996; Simic and Destouni, 1999; Fiori et al., 2009).

The a priori prediction of the transit time distribution under steady-state flow requires knowing the distribution of flow path lengths, the velocity along each flow pathway and the potential space-time variability of the input to the catchment (Lindgren et al., 2004; Darracq et al., 2009; Fiori et al., 2009). Early work using flowline geometries to predict transit time distributions can be found in the groundwater hydrology

Table I. Water transit time distributions for catchment systems

\begin{tabular}{ll}
\hline Name & Reference(s)
\end{tabular}

Exponential

Advection-dispersion (ADE)

Gamma (2 parameters)

Gamma (3 parameters)

Catchment-scale ADE

Stochastic-mechanistic

Deterministic catchment-scale particle tracking
(Eriksson, 1958; Haitjema, 1995)

(Kreft and Zuber, 1978; Maloszewski and Zuber, 1982)

(Kirchner et al., 2000; Scher et al., 2002)

(Amin and Campana, 1996)

(Kirchner et al., 2001)

(Destouni and Graham, 1995; Simic and Destouni, 1999; Foussereau et al., 2001; Lindgren et al., 2004; Rinaldo et al., 2005; Fiori et al. 2009)

(Darracq et al., 2009) 


\section{J. J. MCDONNELL ETAL.}

literature where assumptions of aquifer flow pathways and velocity fields were used to develop theoretical transit time distributions (Eriksson, 1958). Flowline geometries were considered in catchment hydrology in unit hydrograph theory to determine the width function shape based on geomorphological analysis (Rinaldo and Rodriguez-Iturbe, 1996). Therefore, flow lines developed using width functions may also guide the theoretical development of transit time distributions for catchments. Some hypothetical transit time distributions that have been defined based on theory are listed in Table I. Catchments under natural conditions are generally far from steady-state flow conditions due to the high variability of rainfall and ET (see above). Therefore, water velocities and flow pathways are dynamic and highly variable in time and space. Under these conditions, we do not only expect that the mean transit time is time variant, but also the shape of the transit time distributions is time variant [see similar developments for unit hydrograph theory by Rinaldo and Rodriguez-Iturbe (1996)].

Each hypothetical transit time distribution needs to be experimentally tested. In a perfect world, we would be able to directly measure the transit time distribution of a catchment under steady- or unsteady-state conditions. But even in a simple onedimensional system with a well-defined input signal, it seems to be very challenging to differentiate among different shapes of transit time distributions or different processes responsible for the shape (Jury et al., 1982; Bencala and Walters, 1983; Maloszewski et al., 1995). Therefore, there will be little hope to test all our theoretical assumptions even with high-frequency data when considering a catchment as a simple input-output system (Figure 1). However, high-frequency data may enable us under certain conditions to falsify the assumption of a time-invariant transit time distribution and new sensors are now available for testing this (Berman et al., 2009). Theoretical analyses can also help us explore what controls the transit time distribution form. For example, Fiori et al. (2009) show that a rapidly responding soil water system when combined with a subsoil or bedrock system produces transit time distributions that are power law at early time and exponential at late time as inferred from field data by Kirchner et al. (2000). We could also consider multiple tracers to mark different areas in a catchment and hence different flow pathways to assess (i.e. to benchmark for consistency with theory) potential transit time distributions. In all cases, we may include additional measurements of residence and flux concentrations of the tracers in different compartments (unsaturated and saturated zone, stream, etc.) of the catchment. Another approach would be to numerically model the flow pathways and velocities within a catchment and assume certain transport mechanisms (Fiori and Russo, 2008; Darracq et al., 2009). However, this may also be problematic, since we typically use tracers to estimate the transport mechanisms in different media in the first place.

\section{Field research needs}

Recent experimental studies have revealed the complex way in which catchment characteristics and forcing factors influence transit times. We know, obviously, that the mean catchment transit times are orders of magnitude longer (often many years) than the time scale of hydrological (i.e. the storm hydrograph) response to precipitation inputs (Kirchner, 2003). This means that the stream hydrograph responds within minutes to hours of the precipitation input, but the water comprising the hydrograph is often months to years old (note that this suggests a clear difference between the response times associated with pressure propagation and those associated with transport). The influence of topography, geology, soil hydrology and climatic factors on transit time has been demonstrated in specific case studies. For example, recent work by McGuire et al. (2005) has identified the link between transit times and topographic indices in the steep landscape of the western Cascades of Oregon, USA. Hillslope bedrock lithology (and the resulting soil properties developed in these hillslopes) was shown to be a dominant control on mean transit times of soil water in the Marshall Gulch watershed in the Catalina Mts. near Tucson, Arizona (Heidbüchel et al., 2008). In contrast, at Redondo Peak in the Valles Caldera, New Mexico, catchment exposure (aspect and slope) and potentially confounding topographical features explain mean transit time of stream flow (Broxton et al., 2009). In glaciated catchments in Scotland, studies (Rodgers et al., 2005; Soulsby et al., 2006; Soulsby and Tetzlaff, 2008) have shown the importance of soil hydrology as the main control on catchment transit times, although more recent work by Hrachowitz et al. (2009a) has shown the integrative influence of soils, topography and climate on transit times. Apparent contrasts in the identification of first-order controls on transit times appear to reflect geographic differences in key forcing factors and catchment characteristics (Tetzlaff et al., 2009a,b). Reconciling such differences requires understanding of catchments as co-evolved systems where climate, geology, topography, soil cover and land use interact in different ways in response to external forcing to influence hydrological processes.

One field research need is to further understand the linkages between catchment characteristics and hydrological behaviour. We have already seen that different tracers can provide understanding of different elements of the transit time distribution and it 
is, therefore, important that a multi-tracer approach is adopted, if we wish to characterize the full distribution. In addition to conservative input-output tracers, which provide temporal information on system behaviour, there is an important role for other types of tracer that can improve understanding of geographic sources of water and flow pathways. In an ideal world we would label every molecule of water entering a catchment with a different time and space tracer and collect them at the outlet in order to fully characterize the catchment transit time distribution and water sources. Such an experiment would only be practical in a controlled environment such as a laboratory and even then we could only partially label the entire flow domain. In reality, we are restricted to using different natural tracers that can help inform us about processes both spatially and temporally. For example, hydrochemical tracers (e.g. $\mathrm{Si}, \mathrm{Ca}, \mathrm{F}$ ) can provide valuable data pertaining to sources and flow pathways of water (Iorgulescu et al., 2005, 2007; Lischeid, 2008). Naturally occurring environmental isotopes $\left(\right.$ e.g. $\left.{ }^{18} \mathrm{O},{ }^{2} \mathrm{H},{ }^{3} \mathrm{H}\right)$ can provide information about specific ages of water within catchments and are necessary to characterize different components of the transit time distribution.

The major controls on the transit time distribution will vary between landscapes (Devito et al., 2005; Buttle, 2006). This can be better understood by further comparative studies across regions (Tetzlaff $e t$ al., 2009b), which would be facilitated by use of consistent methodologies to allow for sound intercomparison and provision of good ancillary data to characterize the catchment including climate, terrain, soils, geology and vegetation. Tracer studies that compartmentalize the catchment (e.g. soil water residence time (Stewart and McDonnell, 1991), hillslope residence time (McGuire et al., 2007); hyporheic zone residence time (Haggerty et al., 2002) give us better understanding of how different components of the catchment contribute to the overall residence time and can play a role in model testing.

There are a variety of issues that limit the utility of current tracer studies for generating transit time distributions. We typically make the assumption of timeinvariant residence time distributions, which requires an assumption of constant catchment storage volume (see theoretical discussion above). This suggests that we need to include monitoring of catchment storage as auxiliary data (e.g. soil moisture and groundwater level measurement at select/representative sites). Transit time studies are typically biased by excluding the fast (e.g. surface flow, interflow) and very slow (deep groundwater) pathways, which lead to intermediate travel times being overemphasized (as the distribution must integrate to one). This results from experimental sampling design with low temporal resolution and typically low flow oriented sampling and short record lengths, respectively. Tracer selection can help this problem due to the limited age range to which an individual tracer is applicable, suggesting that studies that use multiple tracers with longer records may provide better information. Higher resolution sampling for longer periods has been shown to reduce uncertainty in transit time characterization (Hrachowitz et al., 2009b) and is providing insights into the nature of the transit time distribution (Kirchner et al., 2000). Comparison of a range of sampling schemes of spatial and temporal input and catchment response could help in selecting efficient sampling design through analysis of existing highly detailed datasets. For example, the relative merits of fixed interval and flowweighted sampling should be evaluated.

A particular issue of importance is the characterization of the catchment inputs, which are often assumed to be perfectly known. However, inputs of water and tracer to the catchment system are highly variable in space and time and are a significant source of uncertainty in interpretation of catchment response (McGuire et al., 2005; Hrachowitz et al., 2009a; Persson and Destouni, 2009). In current transit time models, rainfall is transformed into effective input by attempting to account for the influence of soils, vegetation (e.g. occult, throughfall, dry deposition) and terrain position on ET and recharge. In the case of ${ }^{18} \mathrm{O}$ and ${ }^{2} \mathrm{H}$, fractionation effects during the transformation from actual rainfall to effective rainfall needed to be accounted for. Dry and occult deposition in some tracer systems also needs to be taken into account (Page et al., 2007).

It is clear that previous experimental methods, although insightful, have many spatial and temporal limitations that restrict more comprehensive understanding and application in hydrological models. Key challenges for the future involve integrating established methods and new techniques to optimize sampling in a way that is appropriate to the controlling factors in a particular geographical context. This might involve the use of reconnaissance for rapid assessment to determine appropriate monitoring strategies and protocols that are best suited to a specific catchment and motivating question. In many cases, characterizing the short (i.e. sub-daily) and/or long (decadal) tails of the transit time distribution is an important requirement. However, the more intensive investigations needed to do this must be set in the context of climatic variability and the ways in which this affects the transit time distribution. Such advances will minimize data uncertainties and help to maximize the usefulness of data and transit time information for model applications. 


\section{J. J. MCDONNELL ETAL.}

\section{Watershed model needs}

Transit times are a useful concept in hydrology independent of catchment modelling, and many model applications are useful even if the models do not simulate transit time distributions correctly. There are, however, reasons why we may want to be able to realistically simulate transit time using models. The first is improved process understanding; we want our catchment models not only to be capable of simulating runoff but also to do so for the right reasons (Kirchner, 2006). If we can show that a model can predict approximately correct transit time distributions, it is more likely that the model represents a valid description of the catchment processes (conceptually and mathematically). Additionally, if we want to predict water quality for water management purposes, being right for the right reasons (i.e. simulating the correct flow pathways and transit times) obviously becomes essential. Tracer information can also be used to reject model representations of processes (cf. Vaché and McDonnell, 2006; Page et al., 2007).

Secondly, models can facilitate estimation of transit time distributions (Dunn et al., 2007; McGuire et al., 2007; Darracq et al., 2009; Sayama and McDonnell, 2009). This ranges from geomorphic analyses, where transit time distributions are inferred from topography (Kirchner et al., 2001) to distributed models where parameters other than topography such as hydraulic conductivity and drainable porosity are also included (McGuire et al., 2007; Darracq et al., 2009). Although geomorphic analyses provide relative, rather than absolute, information on transit times, dynamic models provide transit times more directly. Furthermore, dynamic models, allow us to 'predict' transit time distributions by simulating imaginary tracer breakthrough curves or implementing time-space accounting, even when observed input and output tracer information is not available. Nevertheless, there are advantages of dynamic models and some critical issues to be addressed. Parameters such as spatially distributed hydraulic conductivities have to be estimated at the catchment scale, where they are difficult to measure, and we have to rely on appropriate process representations (see discussion in Beven (2006b)). In many catchment models, in which the inputs are processed through one or more storage elements, there is a problem of numerical dispersion when simulating tracer fluxes. The numerical dispersion might make the simulations 'look' appealing, but this is of course not an accurate physical representation of solute transport. Rather we should include dispersion intentionally and represent the relevant physical processes. How to do so is an open question, remembering that when applied to macro-dispersion is only a convenient approximate assumption to a complex non-stationary process (and only one component of hydrodynamic dispersion).

Thirdly, models can also be used to investigate and test the effect of assumptions in transit time analyses. Using virtual experiments with (partly) synthetic data we can evaluate these violations. For instance, we can test the effect of uneven distributions of precipitation inputs to a catchment. Contrary to the steady-state assumptions of most transit time analyses, dynamic catchment models simulate both water dynamics and tracer together without assuming the time-invariant transit time distributions or steady conditions. This allows for the investigation of time variant flow pathways and transit times and their effect on, for instance, mean transit times (Lindstrom and Rodhe, 1992; Foussereau et al., 2001; McGuire et al., 2007).

The information content in the precipitation-runoff series is limited and is usually insufficient to constrain catchment models. We often find different model structures and different parameterisations to be equally acceptable given the data we have for model evaluation (Beven, 2006a). Many of us had the naive hope that including additional information, such as ${ }^{18} \mathrm{O}$ time series, would help to better constrain models and to reduce uncertainties. However, the incorporation of tracer data into models often dictates that new model parameters are needed. In particular, the hydrological response that is controlled by celerities in the system might require different effective mixing volumes than the representation of transit time distributions which are controlled by the flow velocities and mixing between stagnant and dynamic storages. In addition, shorter transit times might not be identifiable if the sampling time step is too long. Longer transit times in the system might be associated only with a small proportion of the total mass flux so that accurate identification of the tail of the distribution might depend on the errors in the input and output series. Thus, incorporating tracer data into models may not necessarily constrain or improve models due to the higher dimensionality of the model space and the uncertainties inherent in tracer simulations. One reason is that additional tracer concentration signals are often weaker than the runoff signal. Mass fluxes of tracers might vary more, but these are usually dominated by water flow variations.

Uncertainties obviously hinder differentiating between different hypotheses. Use of dual or multiple tracers can be invaluable in terms of resolving competing hypotheses for explaining differences in catchment function, although again this comes at the cost of increased parameterization. There are multiple sources of uncertainty that affect catchment modelling results. These include uncertainties related to the implicit or explicit conceptual model(s) assumed, 
measurement errors, spatial and temporally variable parameters (e.g. spatial variability of hydraulic conductivity) and sampling uncertainties (e.g. what flow lines does a sample represent) (Beven, 2009; Matott et al., 2009). Such uncertainties must be evaluated because they can obscure the links between processes and characteristics within catchments, and they increase the range of viable alternative models/realizations which can hamper interpretation of model results and make selection of appropriate management or mitigation options much more difficult. Examination of uncertainties can help identify which uncertainties may be most fruitful to try to reduce in future studies, and it helps avoid making errors related to model acceptance/rejection discussed earlier in this section.

An important consideration in estimating mean transit times or transit time distributions in catchments is that inputs (e.g. precipitation, infiltration, contaminant or nutrient inputs) often have substantially larger uncertainties than outputs (e.g. deviations from observed and predicted stream concentrations). However, users of models often assume the input is essentially the 'truth' and that the output is what is most uncertain, which is contrary to above. A good example arises from the highly variable spatial distribution of precipitation inputs that is not typically sampled in an adequate way (see example in McGuire and McDonnell, 2006). Appreciation of the input uncertainties is not only useful for quantification of total uncertainties, but also for it directs more focus on reducing input uncertainties during the experimental design phase or monitoring plan development. Although we have learned a lot about how catchments behave and the implications of mean transit time and the transit time distributions, there remain some major uncertainties that catchment hydrologists must address to improve representation and understanding of flow and transport processes within catchments. Some key uncertainties that should be considered are highlighted below; these are also important areas requiring additional research.

Instantaneous mixing is a common assumption that is invoked in many catchment modelling schemes. However, it is not a good physical representation of actual mixing in the field. The effect of the instantaneous mixing assumption needs further evaluation and alternative models (described earlier) that do not make this assumption can be used. A related issue is that some models (e.g. linked box type models) rely on numerical dispersion to simulate mixing. However, this is not a physical representation of mixing at all, and often the degree of numerical dispersion in models is not adequately evaluated. Other approaches avoid the numerical dispersion problem, but it may be difficult to quantify what the effective dispersion values should be [e.g. see the uncertainty study of a dispersion model in Zhang et al. (2006)]. Dispersion is a scale variant process and coefficients can be difficult to determine for different length scales [see groundwater examples in Gelhar et al. (1992) and specifically for transit time representations of dispersion in Shapiro and Cvetkovic (1988), Cvetkovic and Dagan (1994) and Dagan et al. (2002). Thus, how we represent mixing in a model can be a significant source of uncertainty both from conceptual and parameter uncertainty standpoints (Cvetkovic et al., 1992; Persson and Destouni, 2009).

Different water or solute storage 'zones' within catchments have their own internal transit time distributions that combine to produce the overall catchment transit time distribution (Lindgren et al., 2004). Uncertainties arise about the relative impact or weight of these internal storage transit time distributions on the overall catchment transit time distribution. Such uncertainties not only apply to larger-scale storage zones such as groundwater and the unsaturated zone, but also to smaller-scale zones. Smaller-scale examples include so-called immobile water zones within the unsaturated zone and preferential flow paths, such as macropores. Uncertainties related to our lack of ability to characterize the internal mean transit time or transit time distributions of these zones and their spatial and temporal distributions can be particularly vexing for understanding and representing transport within a catchment.

Another key uncertainty is ET, which is difficult to quantify, yet it can dramatically impact water balance and storage tracer concentrations. It also affects hydraulic gradients, concentrates solutes, and evaporation can shift isotope compositions. Although valuable advances in ET measurements and estimation of the evaporation and transpiration components of ET are being made, an easy and accurate method to quantify total ET is still a hydrological holy grail. This situation has forced catchment modellers to make pragmatic decisions and apply Penman-Monteith (Monteith, 1981), simple water balance, or other convenient approaches to estimate ET. However, we are kidding ourselves if we assume that the uncertainties related to such approaches are minor, especially because ET is often such a dominant part of the catchment water balance. At a minimum, sensitivity analyses or multiple realizations should be made for a range of ET values and/or the distribution of ET over the catchment when these approaches are used. In this way, the effect of ET uncertainties on mean transit time and the transit time distribution can be properly assessed.

In many catchments, snowmelt can be a major control on catchment hydrology. Unfortunately, our ability to quantify the effects of snowmelt inputs is limited 


\section{J. J. MCDONNELL ET AL.}

because snowmelt is difficult to monitor and sample because snowpacks can vary greatly over space and time, and because our suite of snowmelt tracers is not adequate. Stable isotopes $\left({ }^{2} \mathrm{H}\right.$ and $\left.{ }^{18} \mathrm{O}\right)$ have some potential because snowmelt typically has quite negative isotope values. However, complex changes in isotope composition occur during snow metamorphism (Taylor et al., 2001) resulting in temporally and spatially variable isotope values. Characterization and monitoring of snow and snowmelt are clearly areas where additional catchment research is warranted.

Finally, we wish to reiterate the potentially underappreciated importance of old groundwater input to streams and its impact on the mean transit time and transit time distribution for a catchment. The presence of old groundwater contribution to streamflow also has major implications for groundwater storage volume, and the implied volumes of old groundwater based on estimated stream inputs and 'age' will need to be reconciled with a physically based assessment of groundwater storage (e.g. through borehole and/or geophysical measurements). The fact that groundwater bodies can extend outside of the topographic boundary of an individual catchment may also be of prime consideration in light of the catchment water balance. We thus need to have a better understanding of where and when old groundwater inputs are important, and increased use of environmental tracer approaches such as tritium, tritium/helium-3 and CFCs should be an effective way to reduce uncertainties about old groundwater.

\section{Conclusions}

Transit time is a fundamental catchment descriptor that reveals information about the storage, flow pathways and source of water. This commentary has attempted to outline what we know, what we don't know and what we need to know from a field and modelling perspective. Most simply, it is important for the community to note that the mean transit time for water through catchments can be orders of magnitude longer than the timescale of hydrologic response (thus, prompt discharge of old water). Secondly, it is important to acknowledge that we really do not know the shape of the transit time distributions in catchments. We summarize below some of our most pressing science questions in this regard:

1. What are the reasons for differences between ${ }^{18} \mathrm{O}$ and ${ }^{3} \mathrm{H}$-based transit time estimates and how can field experiments using multiple tracers be used to derive a more complete distribution of transit times?

2. How can high temporal and spatial density sampling of precipitation and streamwater be used to develop new non-steady-state transit time distributions at the catchment scale?

3. How can the shape of the transit time distribution be generalized and how useful is a time-invariant representation in a dynamic system? How does the distribution vary (with ambient conditions, from time to time and from place to place)?

4. What are the physical processes and material properties (including heterogeneity at various scales) that control the transit time distribution? How and why do these processes (and the resulting distributions) vary, with time, ambient conditions and place?

5. What is the relationship between the transit time distribution of a more-or-less ideal tracer, and the transit time distribution of non-conservative 'tracers' that have much practical import (nutrients or contaminant, etc.)? Can these differences be adequately summarized simply with a retardation factor (Feng et al., 2004)?

6. How can we deal with the effects of numerical dispersion, immobile water and solute storage zones, and ET partitioning in 'predicting' transit time distributions with a minimal number of additional parameters in hydrologic models?

The questions help define the following four key research needs:

1. We need whole-watershed tracer experiments to define in situ, transit time distributions.

2. We need to develop more rigorous tests generally to better constrain appropriate transit time distributions for a given system.

3. We need more work that relates transit times to geographic, geomorphic, geologic and biogeochemical characteristics of catchments.

4. We need more understanding of the relationship between celerities and velocities in the response of hillslopes and catchments and the best way to parameterize effective storages to reflect the difference in response times.

Overall, transit time distributions of passive tracers provide a critical test of catchment models, by providing an additional constraint that is not directly correlated to the water flux (rainfall-runoff) time series; but is controlled by the same physical processes that transport water through the catchment (and therefore determine the rainfall-runoff behaviour). We hope that this commentary may serve as a benchmarking statement as we proceed to incorporate the concept of transit time more fully into experimental work (for revealing new processes) and watershed modelling (for model structure development and model testing). 


\section{Acknowledgements}

JJM would like to thank the IAEA for support during a research leave in Vienna that bracketed the workshop. The support of Pradeep Aggarwal and staff in the Isotope Hydrology Section was instrumental in facilitating this work. Tina Garland is thanked for final assistance with editing and Jim Buttle is thanked for helpful comments on the final version.

\section{References}

Amin IE, Campana ME. 1996. A general lumped parameter model for the interpretation of tracer data and transit time calculation in hydrologic systems. Journal of Hydrology 179: 1-21.

Bencala KE, Walters RA. 1983. Simulation of solute transport in a mountain pool-and-riffle stream: a transient storage model. Water Resources Research 19: 718-724.

Berman E, Gupta M, Gabrielli C, Garland T, McDonnell JJ. 2009. High-frequency field deployable isotope analyzer for hydrological applications. Water Resources Research 45: 10, DOI: 10.1029/ 2009WR008265.

Beven K. 2006a. A manifesto for the equifinality thesis. Journal of Hydrology 320: 18-36.

Beven K. 2006b. Searching for the Holy Grail of scientific hydrology: $\mathrm{Q}_{1}=(\mathrm{S}, \mathrm{R}, \Delta \mathrm{t}) \mathrm{A}$ as closure. Hydrology and Earth System Sciences 10: 609-618.

Beven KJ. 2009. Environmental Modelling: An Uncertain Future? An Introduction to Techniques for Uncertainty Estimation in Environmental Prediction. Routledge: London; 310.

Broxton PD, Troch PA, Lyon SW. 2009. On the role of aspect to quantify water transit times in small mountainous catchments. Water Resources Research 45: W08427, DOI: 10.1029/2008WR007438.

Buttle J. 2006. Mapping first-order controls on streamflow from drainage basins: the $\mathrm{T}^{3}$ template. Hydrological Processes 20: 3415-3422.

Cvetkovic V, Dagan G. 1994. Transport of kinetically sorbing solute by steady random velocity in heterogeneous porous formations. Journal of Fluid Mechanics 265: 189-215.

Cvetkovic V, Dagan G, Shapiro AM. 1992. A solute flux approach to transport in heterogeneous formations, 2, Uncertainty analysis. Water Resources Research 28: 137-1388.

Darracq A, Destouni G, Persson K, Prieto C, Jarsjö J. 2009. Quantification of advective solute travel times and mass transport through hydrological catchments. Environmental Fluid Mechanics DOI 10.1007/s10652-009-9147-2 (in press).

Destouni G, Graham W. 1995. Solute transport through an integrated heterogeneous soil-groundwater system. Water Resources Research 31: 1935-1944.

Devito K, Creed I, Gan T, Mendoza C, Petrone R, Silins U, Smerdon B. 2005. A framework for broad-scale classification of hydrologic response units on the Boreal Plain: is topography the last thing to consider?. Hydrological Processes 19: 1705-1714.

Dunn SM, McDonnell JJ, Vache KB. 2007. Factors influencing the residence time of catchment waters: a virtual experiment approach. Water Resources Research 43: W06408. DOI:06410.01029/02006WR 005393.

Eriksson E. 1958. The possible use of tritium for estimating groundwater storage. Tellus 10: 472-478.

Etcheverry D, Perrochet P. 2000. Direct simulation of groundwater transit-time distributions using the reservoir theory. Hydrogeology Journal 8: 200-208.

Feng X, Kirchner JW, Neal C. 2004. Measuring catchment-scale chemical retardation using spectral analysis of reactive and passive chemical tracer time series. Journal of Hydrology 292: 296-307.
Fiori A, Russo D. 2008. Travel time distribution in a hillslope: insight from numerical simulations. Water Resources Research 44: W12426, DOI: $10.1029 / 2008 W R 007135$.

Fiori A, Russo D, Di Lazzaro M. 2009. Stochastic analysis of transport in hillslopes: travel time distribution and source zone dispersion. Water Resources Research 45: W08435, DOI: 10.1029/2008WR007668.

Foussereau X, Graham W, Aakpoji A, Destouni G, Rao PSC. 2001. Solute transport through a heterogeneous coupled vadose-saturated zone system with temporally random rainfall. Water Resources Research 37: 1577-1588.

Gelhar LW, Welty C, Rehfeldt KR. 1992. A critical review of data on field-scale dispersion in aquifers. Water Resources Research 28: 1955-1974.

Haggerty R, Wondzell SM, Johnson MA. 2002. Power-law residence time distribution in the hyporheic zone of a 2nd-order mountain stream. Geophysical Research Letters 29: 1640, DOI: 10.1029/2002GL 014743.

Haitjema HM. 1995. On the residence time distribution in idealized groundwatersheds. Journal of Hydrology 172: 127-146.

Heidbüchel I, Troch P, Guardiola-Claramonte M, Rasmussen C, Chorover J. 2008. What controls transit time distributions in a mountainous semi-arid catchment? EOS, Transactions of the American Geophysical Union 89: Fall Meet. Suppl., Abstract H31E-0934.

Hrachowitz M, Soulsby C, Tetzlaff D, Dawson JJC, Malcolm IA. 2009a. Regionalization of transit time estimates in montane catchments by integrating landscape controls. Water Resources Research 45: W05421, DOI:10.1029/2008WR00749.

Hrachowitz M, Soulsby C, Tetzlaff D, Dawson JJC, Dunn SM, Malcolm IA. 2009b. Using long-term data sets to understand transit times in contrasting headwater catchments. Journal of Hydrology 367: 237-248.

Iorgulescu I, Beven KJ, Musy A. 2005. Data-based modelling of runoff and chemical tracer concentrations in the Haute-Mentue research catchment (Switzerland). Hydrological Processes 19: 2557-2573.

Iorgulescu I, Beven KJ, Musy A. 2007. Flow, mixing, and displacement in using a data-based hydrochemical model to predict conservative tracer data. Water Resources Research 43: W03401. DOI:03410.01029/02005WR004019.

Jury WA, Stolzy LH, Shouse P. 1982. A field-test of the transferfunction model for predicting solute transport. Water Resources Research 18: 369-375.

Kirchner JW. 2003. A double paradox in catchment hydrology and geochemistry. Hydrological Processes 17: 871-874.

Kirchner JW. 2006. Getting the right answers for the right reasons: linking measurements, analyses, and models to advance the science of hydrology. Water Resources Research 42: W03S04. DOI:10.1029/2005WR004362.

Kirchner JW, Feng X, Neal C. 2000. Fractal stream chemistry and its implications for contaminant transport in catchments. Nature 403: 524-527.

Kirchner JW, Feng X, Neal C. 2001. Catchment-scale advection and dispersion as a mechanism for fractal scaling in stream tracer concentrations. Journal of Hydrology 254: 82-101.

Kreft A, Zuber A. 1978. On the physical meaning if the dispersion equation and its solutions for different initial and boundary conditions. Chemical Engineering Science 33: 1471-1480.

Lindgren GA, Destouni G, Miller AV. 2004. Solute transport through the integrated groundwater-stream system of a catchment. Water Resources Research 40: W03511. DOI:03510.01029/02003WR002765.

Lindstrom G, Rodhe A. 1992. Transit times of water in soil lysimeters from modeling of oxygen-18. Water, Air, \& Soil Pollution 65: 83-100.

Lischeid G. 2008. Combining hydrometric and hydrochemical data sets for investigating runoff generation processes: tautologies, inconsistencies and possible explanations. Geography Compass 2: 255-280. 


\section{J. J. MCDONNELL ETAL.}

Maloszewski P, Zuber A. 1982. Determining the turnover time of groundwater systems with the aid of environmental tracers. 1. Models and their applicability. Journal of Hydrology 57: 207-231.

Maloszewski P, Zuber A. 1993. Principles and practice of calibration and validation of mathematical models for the interpretation of environmental tracer data. Advances in Water Resources 16: 173-190.

Maloszewski P, Moser H, Stichler W, Trimborn P. 1995. Isotope hydrology investigations in large refuse lysimeters. Journal of Hydrology 167: 149-166.

Maloszewski P, Rauert W, Trimborn P, Herrmann A, Rau R. 1992. Isotope hydrological study of mean transit times in an alpine basin (Wimbachtal, Germany). Journal of Hydrology 140: 343-360.

Matott LS, Babendreier JE, Purucker ST. 2009. Evaluating uncertainty in integrated environmental models: a review of concepts and tools. Water Resources Research 45: W06421, DOI: 10.1029/ 2008WR007301.

McGuire KJ, McDonnell JJ. 2006. A review and evaluation of catchment transit time modeling. Journal of Hydrology 330: 543-563.

McGuire KJ, McDonnell JJ, Weiler M, Kendall C, Welker JM, McGlynn BL, Seibert J. 2005. The role of topography on catchmentscale water residence time. Water Resources Research 41: W05002. DOI:05010.01029/02004WR003657.

McGuire KJ, Weiler M, McDonnell JJ. 2007. Integrating tracer experiments with modeling to assess runoff processes and water transit time. Advances in Water Resources 30: 824-837.

Monteith JL. 1981. Evaporation and surface temperature. Quarterly Journal of Royal Meteorological Society 107: 1-27.

Niemi AJ. 1977. Residence time distribution of variable flow processes. International Journal of Applied Radiation and Isotopes 28: 855-860.

Page T, Beven KJ, Freer J, Neal C. 2007. Modelling the chloride signal at Plynlimon, Wales, using a modified dynamic TOPMODEL incorporating conservative chemical mixing (with uncertainty). Hydrological Processes 21: 292-307.

Persson K, Destouni G. 2009. Propagation of water pollution uncertainty and risk from the subsurface to the surface water system of a catchment. Journal of Hydrology 377(3-4): 434-444.

Rinaldo A, Bertuzzo E, Botter G. 2005. Nonpoint source transport models from empiricism to coherent theoretical frameworks. Ecological Modelling 184: 19-35.

Rinaldo A, Rodriguez-Iturbe I. 1996. Geomorphological theory of the hydrological response. Hydrological Processes 10: 803-829.

Rodgers P, Soulsby C, Waldron S, Tetzlaff D. 2005. Using stable isotope tracers to assess hydrological flow paths, residence times and landscape influences in a nested mesoscale catchment. Hydrology and Earth System Sciences 9: 139-155.

Rodhe A, Nyberg L, Bishop K. 1996. Transit times for water in a small till catchment from a step shift in the oxygen 18 content of the water input. Water Resources Research 32: 3497-3511.

Sayama T, McDonnell JJ. 2009. A new time-space accounting scheme to predict stream water residence time and hydrograph source components at the watershed scale. Water Resources Research 45: W07401, DOI: 10.1029/2008WR007549.

Scher H, Margolin G, Metzler R, Klafter J, Berkowitz B. 2002. The dynamical foundation of fractal stream chemistry: the origin of extremely long retention times. Geophysical Research Letters 29: 1061. 1010.1029/2001GL014123.

Shapiro AM, Cvetkovic V. 1988. Stochastic analysis of solute travel time in heterogeneous porous media. Water Resources Research 24: 1711-1718.

Simic E, Destouni G. 1999. Water and solute residence times in a catchment: Stochastic model interpretation of ${ }^{18} \mathrm{O}$ transport. Water Resources Research 35: 2109-2119.

Soulsby C, Tetzlaff D. 2008. Towards simple approaches for mean residence time estimation in ungauged basins using tracers and soil distributions. Journal of Hydrology 363(1-4): 60-74.

Soulsby C, Tetzlaff D, Rodgers P, Dunn S, Waldron S. 2006. Runoff processes, stream water residence times and controlling landscape characteristics in a mesoscale catchment: an initial evaluation. Journal of Hydrology 325: 197-221.

Stewart MK, McDonnell JJ. 1991. Modeling base flow soil water residence times from deuterium concentrations. Water Resources Research 27: 2681-2693.

Stewart MK, Mehlhorn J, Elliott S. 2007. Hydrometric and natural tracer (oxygen-18, silica, tritium and sulphur hexafluoride) evidence for a dominant groundwater contribution to Pukemanga Stream, New Zealand. Hydrological Processes 21: 3340-3356.

Stumpp C, Stichler W, Maloszewski P. 2009. Application of the environmental isotope delta $\mathrm{O}-18$ to study water flow in unsaturated soils planted with different crops: Case study of a weighable lysimeter from the research field in Neuherberg, Germany. Journal of Hydrology 368: 68-78.

Taylor S, Feng X, Kirchner JW, Osterhuber R, Klaue B, Renshaw CE. 2001. Isotopic evolution of a seasonal snowpack and its melt. Water Resources Research 37: 759-770.

Tetzlaff D, Seibert J, Soulsby C. 2009a. Inter-catchment comparison to assess the influence of topography and soils on catchment transit times in a geomorphic province; the Cairngorm mountains, Scotland. Hydrological Processes 23: 1874-1886.

Tetzlaff D, Seibert J, McGuire KJ, Laudon H, Burns DA, Dunn SM, Soulsby C. 2009b. How does landscape structure influence catchment transit time across different geomorphic provinces?. Hydrological Processes 23: 945-953.

Vaché KB, McDonnell JJ. 2006. A process-based rejectionist framework for evaluating catchment runoff model structure. Water Resources Research 42: W02409. DOI:02410.01029/02005WR004247.

Zhang D, Beven K, Mermoud A. 2006. A comparison of non-linear least square and GLUE for model calibration and uncertainty estimation for pesticide transport in soils. Advances in Water Resources 29: 1924-1933.

Zuber A. 1986. On the interpretation of tracer data in variable flow systems. Journal of Hydrology 86: 45-57. 